Int. J. Electrochem. Sci., 16 (2021) Article ID: 210640

International Journal of

ELECTROCHEMICAL

SCIENCE

www.electrochemsci.org

\title{
Active Species Generation in Gas-liquid Discharge Non-thermal Plasma: Operating Conditions, Influencing Factors, and Mechanisms
}

\author{
Keke Ma ${ }^{1}$, Lu Zhou ${ }^{1, *}$, Bai Yu ${ }^{1}$, Yiying Xin ${ }^{1}$, Zhi Cao ${ }^{1}$,Heping Li $^{2}$, Chengyu Bao ${ }^{2}$, Yuexi Zhou ${ }^{1,3}$ \\ ${ }^{1}$ School of Environment, Tsinghua University, Beijing 100084, P. R. China \\ ${ }^{2}$ Department of Engineering Physics, Tsinghua University, Beijing 100084, P. R. China \\ ${ }^{3}$ Research Center of Environmental Pollution Control Engineering Technology, Chinese Research \\ Academy of Environmental Sciences, Beijing 100012, P.R. China \\ *E-mail: zhoulu@tsinghua.edu.cn
}

doi: $10.20964 / 2021.06 .37$

Received: 7 February 2021 / Accepted: 31 March 2021 / Published: 30 April 2021

In this study, gas-liquid phase non-thermal plasma in a needle-plate reactor was used to evaluate the generation of active species $\left(\cdot \mathrm{OH}, \mathrm{H}_{2} \mathrm{O}_{2}\right.$, and $\left.\mathrm{O}_{3}\right)$. Specifically, the effects of different factors, including initial $\mathrm{pH}$, conductivity, gas flow rate, and solution circulation flow rate, on the generation of these active species were investigated. Tert-butanol (TBA) was chosen as the scavenger of $\cdot \mathrm{OH}$ given that formaldehyde is a specific product of their reaction. The results showed that the generation of $\cdot \mathrm{OH}$ and $\mathrm{H}_{2} \mathrm{O}_{2}$ occurs at a faster rate in acidic solutions than in alkaline and neutral solutions. High-conductivity solutions hindered the generation of these active species, which were also affected by the electrolyte type. Further, oxygen and liquid circulation flow rates had little effect on $\cdot \mathrm{OH}$ and $\mathrm{H}_{2} \mathrm{O}_{2}$ generation in aqueous solutions. However, they exerted a greater impact on ozone mass transfer in gas and liquid phases. Furthermore, the simulation of the effects of UV irradiation, $\mathrm{H}_{2} \mathrm{O}_{2}$ oxidation, and ozone oxidation on the generation of these active species during discharge showed that individually, UV radiation and ozone oxidation had no significant effect on the generation of $\cdot \mathrm{OH}$ and $\mathrm{H}_{2} \mathrm{O}_{2}$. However, various combinations of these processes, especially $\mathrm{UV} / \mathrm{O}_{3} / \mathrm{H}_{2} \mathrm{O}_{2}$ and $\mathrm{UV} / \mathrm{O}_{3}$, significantly enhanced . OH production.

Keywords: gas-liquid discharge, non-thermal plasma, active species, hydroxyl radical, mechanism

\section{$\underline{\text { FULL TEXT }}$}

(C) 2021 The Authors. Published by ESG (www.electrochemsci.org). This article is an open access article distributed under the terms and conditions of the Creative Commons Attribution license (http://creativecommons.org/licenses/by/4.0/). 